\title{
Empreendedorismo social na interface entre comunicação pública e capital social
}

\author{
Social entrepreneurship in the interface between \\ public communication and social capital
}

\section{Emprendedorismo social en la interface entre comunicación pública y capital social}

Maria José da Costa Oliveira

- Pós-doutora, doutora e mestre em Ciências da Comunicação pela Escola de Comunicações e Artes da Universidade de São Paulo (ECA-USP)

- Docente e coordenadora dos cursos de Comunicação Social da Faculdade DeVry/Metrocamp, de Campinas, SP

- Presidente da Associação Brasileira de Pesquisadores de Comunicação Organizacional e de Relações Públicas (Abrapcorp)

- Diretora administrativa da Federação Brasileira das Associações Científicas e Acadêmicas de Comunicação (Socicom) - gestão 2016-2018

- Integra o Grupo de Pesquisa em Comunicação Pública e Comunicação Política (Compol) da ECA-USP

- E-mail: zezecoliveira@gmail.com

\section{Silvana Maria Nader}

- Mestranda em Psicologia na Pontifícia Universidade Católica de Campinas (PUC-Campinas)

- $\quad$ Especialização em Marketing (FGV), Sustentabilidade (Unicamp) e Educação (Ibmec) Graduação em Relações Públicas pela Escola de Comunicações e Artes da Universidade de São Paulo (ECA-USP)

- MBA em Empreendedorismo Social e Responsabilidade Social pela FIA-USP

- Docente na Faculdade Devry/Metrocamp

- Membro do Grupo de Pesquisa em Avaliação Psicológica e Potencial Humano - PUC-Campinas

- Sócia diretora da Mendes \& Nader Comunicação e Responsabilidade Social

- E-mail: silvana@mncom.com.br 


\section{Resumo}

Este artigo, que tem por base a teoria sociopsicológica e a teoria crítica, trata do empreendedorismo social sob a perspectiva da comunicação pública e do capital social. 0 objetivo é analisar como a correlação desses conceitos é capaz de apresentar uma opção para o desenvolvimento social, já que, no contexto de democracia, uma concepção de desenvolvimento não pode estar atrelada apenas à lógica do mercado que privilegia os ganhos particulares em detrimento do interesse público. A noção de empreendedor social passa a ser útil sob o ponto de vista da viabilidade de ações que visem à sustentabilidade do terceiro setor e de outras perspectivas de atuação social, que, mesmo se valendo de processos de gestão, contrapõem a visão de competição com a visão de cooperação; valoriza o capital social ao invés de evidenciar o capital econômico; ressignifica a lógica capitalista para uma vertente mais humana, em que a questão econômica sirva ao desenvolvimento social.

\section{PALAVRAS-CHAVE: EMPREENDEDORISMO SOCIAL・TERCEIRO SETOR・COMUNICAÇÃO・CAPITAL SOCIAL.}

\section{Abstract}

This article, which is based on socio-psychological theory and critical theory, addresses the social entrepreneurship from the perspective of public communication and social capital. The purpose is to analyze how the correlation between those concepts can present an option for social development, since, in the context of democracy, a conception of development cannot be tied only to the logic of the market that privileges the private gains to the detriment of the public interest. The notion of a social entrepreneur becomes relevant by the perspective of the feasibility of actions aimed at the sustainability of the third sector and other perspectives of social action, which, although using management processes, oppose the view of competition with the view of cooperation; it values social capital rather than evidencing the economic capital; it creates a new meaning for the capitalist logic to a more human side, in which the economic topic serves the social development.

\section{KEYWORDS: SOCIAL ENTREPRENEURSHIP • THIRD SECTOR・COMMUNICATION•SOCIAL CAPITAL.}

\section{Resumen}

Este artículo, que se basa en la teoría sociopsicológica y la teoría crítica, trata del emprendedorismo social desde la perspectiva de la comunicación pública y del capital social. El objetivo es analizar cómo la correlación de estos conceptos es capaz de presentar una opción para el desarrollo social, ya que, en el contexto de la democracia, una concepción de desarrollo no puede estar ligada sólo a la lógica del mercado que privilegia las ganancias particulares en detrimento del interés público. La noción de emprendedor social pasa a ser útil desde el punto de vista de la viabilidad de acciones que apunte a la sostenibilidad del tercer sector y de otras perspectivas de actuación social, que, aun valiéndose de procesos de gestión, contrapone la visión de competencia con la visión de cooperación; valoriza el capital social en lugar de evidenciar el capital económico; resignifica la lógica capitalista hacia una vertiente más humana, en que la cuestión económica sirva al desarrollo social. 
m tema que relacione terceiro setor, empreendedorismo social, comunicação pública e capital social poderia ser tratado sob a perspectiva de muitas teorias. Todavia, neste artigo, que tem como ênfase a comunicação, opta-se pelas tradições sociopsicológica e crítica (Craig, 2007).

A escolha da teoria sociopsicológica se dá à medida que a comunicação passa a ser teorizada como expressão, interação e influência, diante de situação que exige a manipulação de causas de comportamento para alcançar resultados específicos.

A abordagem sob o ponto de vista sociopsicológico é plausível, neste artigo, pelo fato de a comunicação poder refletir a capacidade das pessoas em grupos de afetarem umas às outras, sendo coerente com o objeto de estudo em questão, já que na tradição sociopsicológica a comunicação é conceituada como um processo de interação social.

Vale destacar, porém, que há entre os autores dessa tradição algumas posições diferentes. Allport (1919, apud Craig, 2007), por exemplo, argumenta que a unidade essencial de estudo na psicologia social não deve ser o grupo, mas sim o indivíduo em um contexto de grupo. Enquanto isso, Poole (2007) considera que a ênfase atual é no trabalho em equipe, na qualidade, na responsabilidade social e no empoderamento no discurso social, argumentando que os teóricos da comunicação deverão prestar mais atenção aos fenômenos da comunicação em grupo.

Todavia, essas posições diferentes são por nós contempladas, uma vez que a análise parte do indivíduo como empreendedor social, mas se reflete no trabalho em equipe, o que demanda, inclusive, uma abordagem especial sobre capital social.

Ainda que a tradição sociopsicológica demonstre sua capacidade de embasar nosso trabalho, que tem como objeto de estudo o papel da comunicação no desenvolvimento do empreendedorismo social, entendemos que o tema necessita do embasamento da teoria crítica, já que a comunicação, na presente análise, também é vista como alternativa para a práxis, que possibilita o pensamento crítico e tem o potencial de sugerir caminhos para a ação social e política.

Nesse sentido, ainda que a teoria crítica conte com uma série de abordagens, aqui a consideramos com base nos pensadores da Escola de Frankfurt, já que é nessa perspectiva que se tem como característica maior a ênfase em seus critérios específicos de análise, denunciando a repressão e o controle social. Para os autores que a integram, uma sociedade sem exploração é a única alternativa para que haja justiça, liberdade e democracia, aspectos que são mobilizadores para o empreendedorismo social.

Portanto, ao tratar do tema deste artigo, essa perspectiva se alinha com o mesmo, uma vez que, conforme sintetizado na matriz de Craig (2007), a teoria crítica permite partir de suposições sobre o conhecimento, considerando a comunicação teorizada como reflexão discursiva. Esta se fundamenta sobre a prática da teoria identificada na ideologia presente, na dialética utilizada, na opressão percebida, na conscientização, nas ações de resistência e nas formas de emancipação que ocorrem na sociedade.

Assim, nossa pesquisa considera valores que são determinantes na percepção da formação do cidadão no contexto democrático, tais como liberdade, igualdade e razão, enfatizados na discussão que produz consciência, visão.

Portanto, nosso propósito é fazer uma abordagem teórica, com base nas teorias sociopsicológica e crítica, que passa a ser contemplada a partir de análises sobre conceitos fundamentais, expostos a seguir. 


\section{DESENVOLVIMENTO SOCIAL, TERCEIRO SETOR E EMPREENDEDORISMO SOCIAL}

No Brasil, a Constituição Federal de 1988, vista como "constituição cidadã", instaurou o Estado Democrático de Direito, que tem como princípio a corresponsabilidade do cidadão e do governo na formação do Estado e na defesa do interesse público, diminuindo as fronteiras entre o público e o privado e abrindo espaço para a atuação da sociedade em espaços até então exclusivos do Estado.

Para Lemos (2008, p. 153), o processo de redemocratização do país, iniciado no final da década de 1970 e durante a primeira metade da década de 1980, introduziram na cultura brasileira uma revolução nas formas de gestão das políticas. Em relação aos desafios sociais e ambientais que ainda persistem, Trigueiro (2012) defende que precisamos de um novo modelo econômico que assegure a produção da riqueza, mas também a geração de emprego e renda, em contraposição ao modelo hegemônico no mundo hoje, que é ecologicamente predatório, socialmente perverso e politicamente injusto.

Capra (1982) defende que uma resolução para esses desafios só poderá ser implementada se a estrutura da própria teia (a sociedade como um todo) for mudada, o que envolverá transformações profundas em nossas instituições sociais, em nossos valores e nossas ideias. Para Oliveira (2004), nesse contexto, as virtudes sociais ganham destaque pois a interlocução entre os diferentes setores exige uma base de confiança, de transparência, de ética e de responsabilidade para o exercício da cidadania e atendimento ad interesse público.

Entretanto, cabe o reconhecimento de que não é possível dissociar o crescimento econômico em longo prazo de um país sem progresso social e preservação ambiental. Assim, o desenvolvimento social depende de uma ação colaborativa entre governo, empresas e o chamado terceiro setor, foco de interesse deste artigo.

0 conceito de terceiro setor é controverso e não há unanimidade acadêmica em relação a essa terminologia utilizada para identificar as atividades da sociedade civil que não se enquadram na categoria das atividades estatais (primeiro setor, representado por entes da administração pública) ou das atividades de mercado (segundo setor, representado pelas empresas com finalidade lucrativa). Szazi (2003), denomina o terceiro setor como um novo ator social, formado por um conjunto de agentes privados com fins públicos, cujos programas visam atender direitos sociais básicos, combater exclusão social e proteger o patrimônio ecológico brasileiro.

Para Pereira (2010), estariam incluídas no terceiro setor organizações constituídas sob a modalidade deassociações ou fundações. Portanto, para o autor, caracterizam-se como organizações de interesse social, ou seja, convenientes à sociedade, tanto as organizações de interesse ou caráter público, que são aquelas que objetivam o benefício de toda a sociedade ou de segmentos do conjunto da sociedade (entidades assistenciais, beneficentes, filantrópicas, de defesa de direitos, de origem empresarial - "braço social" - etc.), quanto as organizações de ajuda mútua ou de autoajuda, que objetivam defender interesses coletivos, mas num círculo restrito, específico, de pessoas (associações de classe, associações de moradores, associações comerciais, clubes sociais, recreativos e esportivos etc.). 0 autor considera que no terceiro setor não estão incluídos os partidos políticos, os sindicatos, os serviços sociais autônomos e as organizações religiosas, por possuírem finalidade, natureza ou legislação específicas. Mas hoje verifica-se que, além da forte atuação das organizações do terceiro setor, experiências práticas de soluções para problemas sociais são implantadas por atores da sociedade civil por meio de iniciativas inovadoras que dão corpo ao fenômeno conhecido como empreendedorismo social (Austin, Stevenson e Wei-Skillern, 2006; Melo Neto e Froes, 1999). 
0 conceito de empreendedorismo social é recente e refere-se a atividades inovadoras, mas com objetivos de transformação social, que, em vez de criar produtos ou serviços com finalidades comerciais e lucrativas, produzem mudanças em benefício da sociedade. Trata-se de uma forma relevante de responder aos desafios sociais quando nem o mercado e nem o setor público conseguem atuar com efetividade (Sekliuckiene; Kisielius, 2015).

Mesmo que envolvam organizações sem fins lucrativos, estas passam a assumir uma postura empreendedora mais arriscada e inovadora na implantação de conceitos e práticas de marketing, planejamento estratégico e de sistemas de análise e controle de gestão necessários para sua sustentabilidade (Roper; Cheney, 2005), não se constituindo em filantropia ou caridade porque buscam soluções sustentáveis para os principais problemas sociais, favorecendo o empoderamento, a responsabilidade e o comprometimento dos envolvidos com a causa de forma autônoma (Nga; Shamuganathan, 2010).

Atribui-se a difusão do termo empreendedorismo social a Bill Drayton fundador da Ashoka, organização mundial sem fins lucrativos, pioneira no campo da inovação social. Para a Ashoka Brasil (Ashoka, 2017), empreendedores sociais aliam pragmatismo, compromisso, com resultados e visão de futuro para realizar transformações sociais de relevante impacto, e por meio da sua atuação aceleram o processo de mudanças e inspiram outros atores a se engajarem em torno de uma causa comum.

De acordo com a Ashoka, que completou trinta anos de atuação no Brasil em 2016, no empreendedorismo social os desafios socioambientais são encarados olhando sistemicamente para as causas, e o problema se torna uma ação prática de inovação social que envolve sensibilização, diálogo, mobilização e relacionamento com grupos de interesses diversos. 0 objetivo é atuar em rede, multiplicar experiências e em muitos casos transformar a ideia inicial em política pública, para que possa ganhar capilaridade e assim ampliar seu impacto.

Em função disso, o empreendedorismo social é cada vez mais reconhecido como uma solução para os principais problemas que afetam nossa sociedade (Johnson, 2000; Sud, VanSandt e Baugous, 2009) em especial em contextos onde existam problemas socioeconômicos, ambientais e culturais relevantes sem o apoio de instituições que enfrentam essas falhas (Dacin, M.; Dacin, P.; Tracey, 2010).

O empreendedorismo social refere-se a iniciativas que estimulam a participação coletiva e o sentimento de conexão das pessoas com sua cidade, terra e cultura, por meio de novas ideias e soluções sustentáveis que promovem a melhoria de sua qualidade de vida, entre elas educação e inclusão digital, acesso à moradia de baixo custo, temas ambientais, segurança alimentar e nutricional, diversidade, assistência social de forma ampla, economia solidária, direitos humanos, entre outros (Novaes; Gil, 2009).

Cabe destacar a capacidade desses empreendimentos sociais para inspirar, atrair e mobilizar esforços de parceiros comerciais e não comerciais, donativos, voluntários na criação de riqueza social, reforçando o caráter de engajamento participativo e coletivo na atividade (Zahra et al., 2009).

Apesar de a dimensão individual normalmente ser muito valorizada na descrição da atuação dos empreendedores sociais (inovadores e com ampla visão), Campos e Duarte (2013) afirmam que essa afirmação pode levar à conclusão de que um empreendimento bem-sucedido depende apenas do esforço individual desse empreendedor, mas, na verdade, é fundamental a dimensão social ou coletiva do trabalho nesse contexto, mais bem representado como um processo associativo e de redes.

Da mesma forma, conforme Dhesi (2010), a comunicação é fundamental para o empreendedorismo social, não só por facilitar o desenvolvimento das atividades e a interação com diferentes segmentos, como também pelo caráter responsivo, de dar respostas adequadas às queixas e necessidades da sociedade, o que contribui para a efetividade do seu trabalho. 
Para Mumby (2010), a comunicação está no centro da condição humana, deixando de ser somente o meio pelo qual pensamentos, sentimentos e ideias são transmitidos, mas sim o que os torna possíveis. Para o autor, a comunicação humanizada exige que consideremos o "outro", mas não como alguém que precisa ser incorporado em nossa visão específica de mundo. Ao invés disso, o "outro" é aquele que apresenta um horizonte de possiblidades diferente do nosso e que representa risco para nós, porque engajar-se no seu horizonte nos abre a possibilidade de mudança e transformação.

Outros autores, como Baron e Shane (2007), destacam a importância do capital social no empreendedorismo social utilizado como recurso ou ativo que resulta de estreitas relações entre os indivíduos em uma organização ou outras estruturas sociais, isto é, relacionamentos caracterizados por apreciação recíproca, mútuo respeito e identificação estreita com os outros e com a organização.

Em função da importância que a comunicação e o capital social adquirem quando se trata de empreendedorismo social, apresenta-se, a seguir, uma análise mais detalhada acerca desses conceitos e suas interrelações.

\section{CAPITAL SOCIAL E COMUNICAÇÃO}

Se a comunicação, tendo por base a teoria sociopsicológica, conforme mencionado anteriormente, pode refletir a capacidade de as pessoas em grupo afetarem umas às outras, num processo de interação social, quando se trata de empreendedorismo social uma questão que emerge é justamente a condição de estabelecimento de vínculos entre membros dispostos a agir para uma profunda mudança social.

Ainda que o termo empreendedor social seja conceituado a partir do indivíduo, que alia pragmatismo, compromisso com os resultados e visão de futuro para realizar transformações sociais de relevante impacto (Ashoka, 2017), interessa também considerar a visão e a capacidade desses empreededores em se aliarem a outros membros para que os resultados efetivos sejam gerados.

Nesse sentido, justifica-se a importância de se analisar o conceito de capital social, que está intimamente ligado às redes sociais e de comunicação, disponíveis para as interações dos agentes sociais (Matos, 2009, p. 101). E é essa noção que se integra com a concepcão de Poole (2007) quando defende, por meio da teoria sociopsicológica, a ênfase no trabalho em equipe, na qualidade, na responsabilidade social e no empoderamento no discurso social.

Criar vínculos de confiança diante de objetivos com os quais se dedicam os empreendedores sociais exige a constituição de uma rede social dimensionada pela confiança que os membros atribuem aos participantes e às consequências associadas a esse sentimento (Matos, 2007, p. 55).

Para Albagli e Maciel $(2002$, p. 1) a interação e a cooperação se dão em ambientes mais propícios ao empreededorismo, já que nesse contexto assumem novo papel os sistemas de relações entre os diferentes atores, cuja densidade e cujo caráter inovador podem favorecer processos de crescimento e mudança, em que se desenvolve a atividade empreendedora, produtiva e inovadora. Assim, é de se pressupor que o perfil dos empreendedores sociais seja associado à habilidade de relacionamento, de associação e de conduta que expresse confiança, já que, de acordo com Coleman (apud Fukuyama, 1996, p. 25), capital social é definido como a capacidade de as pessoas trabalharem juntas visando a objetivos comuns em grupos e organizações. 
Essa capacidade de associação depende, por sua vez, do grau em que as comunidades compartilham normas e valores e se mostram dispostas a subordinar interesses individuais aos de grupos maiores, permitindo emergir a confiança, que, segundo Fukuyama (1996), tem um grande e inestimável valor econômico.

Matos (2009, p. 37) concorda com Coleman, para quem o capital social pode ser encontrado em dois tipos de estrutura: nas redes sociais que funcionam num espaço fechado (um clube, associação ou sindicato, com suas próprias normas e sanções) ou numa organização social ou instituição com um objetivo específico (empresa, governo, associação cultural, partido politico, ONG).

Vale e outros (2006, p. 46) consideram que o capital social se manifesta por meio das redes sociais que tornam a cooperação e a ação coletiva para benefício mútuo, no interior das organizações, grupos e comunidades, contribuindo para a percepção de que o empreendedor social desenvolva a capacidade de construir e manter redes sociais de cooperação mais amplas, uma vez que visa a causas de interesse público.

É oportuno, em função da proposta deste artigo, reconhecer que capital social tem sido abordado sob a perspectiva individual e comunitária, sendo que o foco da primeira está relacionado a como indivíduos têm acesso e usam recursos embutidos em redes sociais, baseadas em relações de confiança e reciprocidade, para obter ou preserver ganhos. "Esse tipo de análise enfatiza uma visão instrumental dos relacionamentos, focalizando os benefícios individuais de um modo que não se adequa facilmente aos benefícios cívicos mais amplos ressaltados por outras abordagens sobre capital social" (Albagli; Maciel, 2002).

Todavia, a perspectiva que mais se alinha com os propósitos deste artigo é a que focaliza o capital social em nível comunitário, considerando a maneira como certos grupos desenvolvem e mantêm mais ou menos capital social como um ativo coletivo e como tal ativo pode melhorar a qualidade de vida dos membros da comunidade.

Salienta-se que capital social comunitário pode facilitar: o compartilhamento de normas pelo grupo e a sanção de indivíduos transgressores; o desenvolvimento de confiança entre os membros da comunidade; a resolução de conflitos por líderes ou por uma judicatura institucionalizada; a mobilização e gestão de recursos comunitários; a cooperação coordenada e a geração de espaços e estruturas de trabalho em equipe (Albagli; Maciel, 2002).

Ainda que parte dos estudiosos considerem que capital social é tanto coletivo como individual, concordamos com a concepção de Putnam (2006), para quem capital social pertence mais a grupos e nações do que a indivíduos. Coleman (1988), também concorda com a perspectiva coletiva do capital social, destacando-o como gerador de bens públicos, não sendo caracterizado como uma propriedade privada, divisível ou alienável, mas sim como um atributo da estrutura na qual o indivíduo se encontra inserido. Portanto, para Coleman o capital social beneficia conjuntos, não indivíduos.

Assim, são características do capital social o compartilhamento de normas, valores, atitudes, relações de confiança e comprometimento com a comunidade ou sociedade. E, nesse sentido, emerge o papel da comunicação, já que, conforme aponta Matos (2009, p. 214) quando cita Hartman e Lenk (2001), a comunicação pode potencializar o capital social e o cumprimento de metas negociais, sendo um ativo intangível capaz de contribuir para o capital social, ativo da mesma natureza.

Esse movimento de aproximação entre a noção de capital social e a de comunicação oferece a possibilidade de pensar na constituição dos indivíduos como cidadãos e atores cívicos com base nas interações que estabelecem nas redes sociais, sejam elas organizacionais e/ou cívicas (Matos, 2009, p. 218). 
Dessa forma, a constituição de capital social é capaz de facilitar o engajamento dos cidadãos nos assuntos que afetam a coletividade, por vínculos de confiança que são estabelecidos. E isso provoca a necessidade de se estabelecerem estratégias coletivas, voltadas a promover, de acordo com Vale e outros (2006, p. 46), relações de confiança mútua, senso de propósito e capacidade de trabalho coletivo, elementos subjacentes ao conceito de capital social.

Mesmo que a relação entre capital social e comunicação já esteja contemplada até aqui, dada a importância que adquire a capacidade de conversação por parte dos empreendedores sociais, a presente análise demanda uma abordagem especial sobre o conceito de comunicação pública, justamente por este representar a percepção de comunicação em contextos democráticos, em função de sua natureza de comprometimento com a cidadania e com a promoção de interlocução com a sociedade visando ao interesse público.

Nessa abordagem emerge a fundamentação na teoria crítica, já que a comunicação pública é vista como alternativa para a práxis, que possibilita o pensamento crítico e tem o potencial de sugerir caminhos para a ação social e política.

Para Matos (2007), comunicação pública evoca pluralidade de estilos, gêneros, pontos de vista, opiniões, visões de mundo. E essa pluralidade evidencia a importância do diálogo, dos debates, das discussões e das deliberações que provocam a tomada de decisão em situações que impactam a sociedade e, dessa forma, demonstra total coerência com as demandas do empreendedorismo social, que se refere justamente a iniciativas que estimulam a participação coletiva e o sentimento de conexão das pessoas por meio de novas ideias e soluções sustentáveis (Novaes; Gil, 2009).

De acordo com Weber (2017, p. 24), a complexidade de operar o conceito de comunicação pública reside na sua vinculação ao paradigma e à utopia da esfera pública de Habermas', que valoriza a comunicação, o debate público e, consequentemente, a deliberação, dirigidos pelo interesse público.

Conforme endossa Matos (2007, p. 47), comunicação pública pode ser entendida como espaço plural para a intervenção do cidadão no debate das questões de interesse público, o que indica que a comunicação aqui ganha uma percepção crítica, já que passa a ser teorizada como reflexão discursiva, estando fundamentada sobre a prática da teoria identificada na ideologia presente, na dialética utilizada, na opressão percebida, na conscientização, nas ações de resistência e nas formas de emancipação que ocorrem na sociedade.

A partir do debate gerado no espaço público, entendemos o potencial para estimular o surgimento de empreendedores sociais, capazes de vislumbrar possibilidades de atuação, que contribuam para a transformação social, considerando valores que são determinantes na percepção da formação do cidadão no contexto democrático, tais como liberdade, igualdade e razão, enfatizados na discussão que produz consciência, visão.

Interessante incluir a contribuição de Haswani (2011, p. 82) que destaca a comunicação pública como processos diversos, que fazem interagir os atores públicos e também os privados, na perspectiva de ativar a relação entre o Estado e os cidadãos, com o intuito de promover um processo de crescimento civil e social.

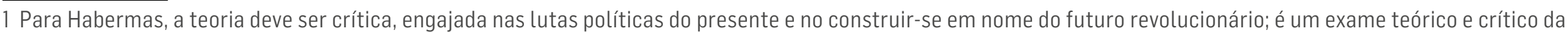

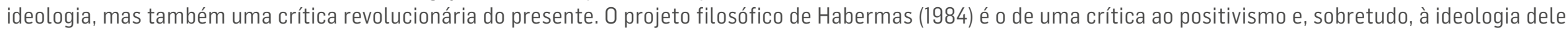
resultante, ou seja, o tecnicismo.
} 
Rosso e Silvestrin (2013) também contribuem para a análise de aproximação entre o conceito de comunicação pública e empreendedorismo social ao concluírem que a comunicação pública é a esperança para se ampliar a democracia, tornando o cidadão corresponsável nas questões de interesse público e que afetam a vida em sociedade.

Daabordagem realizada, é possível identificar a relevância que a comunicação pública adquire diante do empreendedorismo social, já que o interesse público é um aspecto comum a esses conceitos. Além disso, a comunicação pública, como espaço de debate, de interlocução e de deliberação, amplia as possibilidades de qualidade democrática ${ }^{2}$ e revela a essencia do empreendedorismo social, dentro de um amplo processo social que o diferencia do empreendedorismo tradicional, com o fortalecimento da causa defendida por meio do engajamento, do diálogo e da participação, viabilizados com o capital social constituído.

\section{CONSIDERAÇÕES FINAIS}

O contexto democrático, de participação e engajamento cívico é o cenário que propícia o surgimento do empreendedorismo social. Assim, além de se revelar como uma alternativa para se alargar as possibilidades de transformação social, 0 empreendedorismo social tem condição de ser analisado sob a perspectiva da comunicação (pública), que tem em vista 0 debate, as trocas argumentativas, voltadas ao interesse público.

É em vista desse potencial existente junto aos empreendedores sociais, que também decorre o conceito de capital social, que evidencia a importância da estruturação de laços sociais, permitindo a atuação em rede e ampliação de seu impacto para o alcance dos objetivos de transformação social.

Afinal, no empreendedorismo social os desafios socioambientais demandam um olhar sistêmico, que envolve sensibilização, diálogo, mobilização e relacionamento com grupos de interesses diversos.

Conforme já assinalado neste artigo, de acordo com Zahra e outros (2009), empreendimentos sociais têm a capacidade de inspirar, atrair e mobilizar esforços de parceiros comerciais e não comerciais, donativos, voluntários na criação de riqueza social, reforçando o caráter de engajamento, participativo e coletivo da atividade, a ponto de estimular a parceria entre público e privado.

Da análise aqui realizada, conclui-se que o alcance dos objetivos de um empreendimento social depende de uma concepção coletiva do trabalho, do interesse público assegurado com a causa, do processo associativo, do engajamento e de redes que é capaz de estabelecer por meio dos espaços de debate e interlocuções, e que, por isso mesmo, exige sua integração com as noções de capital social e de comunicação pública.

\section{REFERÊNCIAS}

ALBAGLI, Sarita; MACIEL, Maria Lúcia. Capital social e empreendedorismo local. Universidade Federal do Rio de Janeiro. 2002. Disponível em: <http://www.redesist. ie.ufrj.br/nts/nt33/F223_SaritaMLucia.PDF> acesso em 30/04/2017

ASHOKA. Ashoka Brasil. 2017. Disponível em: <http://brasil.ashoka.org/quem-somos>. Acesso em: jan. 2017.

2 Maria Helena Weber defende a comunicação pública como indicador da qualidade da democracia. 
AUSTIN, James; STEVENSON, Howard; WEI- SKILLERN, Jane. Social and comercial entrepreneurship: same, different, or both? Entrepreneurship theory and practice, v. 30, n. 1, p. 1-22, 2006.

BARON, Robert A.; SHANE, Scott A. Empreendedorismo: uma visão do processo. São Paulo: Thomson Lerarning, 2007.

CAMPOS, Nédson Antônio; DUARTE, Francisco J. da Castro Moura. A dimensão social da atividade empreendedora. Cadernos de Psicologia Social do Trabalho, v. 16, n. especial, p. 13-23, 2013.

CAPRA, Fritjof. O ponto de mutação: a ciência, a sociedade e a cultura. São Paulo: Cutrix, 1982.

COLEMAN, James S. Social capital in the creation of human capital. American Journal of Sociology, n. 94 (suplemento), 1988.

CRAIG, Robert T; MULLER, Heidi L. Theorizing communication: reading across traditions. USA: Sage Publications, Inc., 2007.

DACIN, M. Tina; DACIN, Peter A.; TRACEY, Paul. Social entrepreneurship: a critique and future directions. Organization Science, v. 22, n. 5, p. 1203-1213, 2011.

DHESI, Autar S. Diaspora, social entrepreneurs and community development. International Journal of Social Economics, v. 37, n. 9, p. 703-716, 2010. Doi: 10.1108/03068291011062498.

DUARTE, Jorge (Org.). Comunicação pública: estado, mercado, sociedade e interesse público. São Paulo: Atlas, 2007.

FUKUYAMA, Francis. Confiança: valores sociais e criação de prosperidade. Lisboa: Gradiva, 1996.

HABERMAS, Jürgen. The theory of communicative action: reason and the rationalizalion of society. Vol. 1. Boston, MA: Beacon Press, 1984.

HASWANI, Mariângela Furlan. Comunicação pública 360 graus e a garantia de direitos. In: KUNSCH, Margarida M. Krohling (Org.). Comunicação pública, sociedade e cidadania. São Caetano do Sul, SP, Difusão, 2011.

JOHNSON, Sherrill. Literature review on social entrepreneurship. Canadian Centre for Social Entrepreneurship, Nov. 2000. Disponível em: <https://www.researchgate.net/publication/246704544_Literature_Review_Of_Social_Entrepreneurship>.

LEMOS, Pedro Rocha. Politicas públicas, meio ambiene, gestão participativa. In: PÁDUA, Elisabete M. M.de; MATALLO JR., Heitor (Orgs.). Ciências sociais, complexidade e meio ambiente: interfaces e desafios. Campinas, SP: Papirus, 2008.

MATOS, Heloiza. Comunicação pública, esfera pública e capital social. In: DUARTE, Jorge. Comunicação pública: estado, mercado, sociedade e interesse público. São Paulo: Atlas, 2007.

Capital social e comunicação: interfaces e articulações. São Paulo: Summus, 2009.

MELO NETO, Francisco Paulo de; FROES, César. Responsabilidade social e cidadania: a administração do terceiro setor. Rio de Janeiro: Qualitymark, 1999.

MUMBY, Dennis, K. Reflexões críticas sobre a comunicação e humanização nas organizações. In: KUNSCH, Margarida M. Krohling (Org.). Comunicação como fator de humanização nas organizações. São Caetano do Sul, SP: Difusão, 2010. 
NGA, Joyce Koe Hwee; SHAMUGANATHAN, Gomathi. The influence of personality traits and demographic factors on social entrepreneurship start up intentions. Journal of Business Ethics, v. 95, n. 2, p. 259-282, 2010. Doi:10.1007/s10551-009-0358-8.

NOVAES, Marcos B. Carneiro de; GIL, Antonio Carlos. A pesquisa-ação participante como estratégia metodológica para 0 estudo do empreendedorismo social em administração de empresas. Revista de Administração Mackenzie, v. 10, n. 1, 2009.

OLIVEIRA, Maria José da Costa. Comunicação pública e os setores não estatais. In: Comunicação pública. Campinas: Alínea Editora. 2004. p. 187-201,

PEREIRA, Rodrigo Mendes. Terceiro setor. identificando suas organizações e propondo um novo conceito. São Paulo: OAB-SP, 2010.

POOLE, Marshall. The small group should be the fundamental unit of communication research. In: CRAIG, Robert; MULLER, Heidi (Orgs). Theorizing communication: readings across traditions. Los Angeles: Sage, 2007.

PUTNAM, Robert D. Bowling alone: le déclin du capital social aux États-Unis. In: BEVORT, Antoine; LALLEMENT, Michel (Orgs.). Le capital social: performance, équité et réciprocité. Paris: La Décourverte, 2006.

ROPER, Juliet; CHENEY, George. The meanings of social entrepreneurship today. In: Corporate social responsibility. UK: Palgrave Macmillan, 2006. p. 255-267.

ROSSO, Gisele; SILVESTRIN, Celsi Brönstrup. Comunicação pública como prática de responsabilidade social das organizações públicas. Organicom - Revista Brasileira de Comunicação Organizacional e Relações Públicas, v. 10, n. 18, p. 231-243, 2013.

SEKLIUCKIENE, Jurgita; KISIELIUS, Eimantas. Development of social entrepreneurship initiatives: a theoretical framework. Procedia - Social and Behavioral Sciences, v. 213, p. 1015-1019, 2015.

SUD, Mukesh; VANSANDT, Craig V.; BAUGOUS, Amanda M. Social entrepreneurship: the role of institutions. Journal of Business Ethics, v. 85, n. 1, p. 201-216, 2009. Doi: 10.1007/s10551-008-9939-1.

SZAZI, Eduardo. Terceiro setor. regulação no Brasil. 3. ed. São Paulo: Peirópolis, 2003.

TRIGUEIRO, André. Mundo sustentável 2: novos rumos para um planeta em crise. São Paulo: Editora Globo, 2012.

VALE, Gláucia M. Vasconcellos et al. Capital social e suas implicações para o estudo das organizações. Organizações \& Sociedade [online], v. 13, n. 36, jan./mar. 2006.

WEBER, Maria Helena. Nas redes de comunicação pública, as disputas possíveis de poder e visibilidade. In: WEBER, Maria Helena; COELHO, Marja Pfeifer; LOCATELLI, Carlos (Orgs.). Comunicação pública e política: pesquisa e práticas. Florianópolis: Insular, 2017.

ZAHRA, Shaker A. et al. A typology of social entrepreneurs: Motives, search processes and ethical challenges. Journal of Business Venturing, v. 24, n. 5, p. 519-532, 2009. Doi:10.1016/j.jbusvent.2008.04.007.

Texto recebido em 22.05.2017 e aprovado em 10.05.2017. 